\title{
circCRAMP1L is a novel biomarker of preeclampsia risk and may play a role in preeclampsia pathogenesis via regulation of the MSP/RON axis in trophoblasts
}

Yonggang Zhang ${ }^{1}$, Hongling Yang ${ }^{2 *}$, Yipeng Zhang ${ }^{1}$, Junzhu Shi ${ }^{1}$ and Ronggui Chen ${ }^{1}$

\begin{abstract}
Background: Preeclampsia is a severe disease in pregnant women, which is primarily managed by early screening and prevention. Circular RNAs (circRNAs) have increasingly been shown to be important biological regulators involved in numerous diseases. Further, increasing evidence has demonstrated that circRNAs can be used as diagnostic biomarkers. This study was conducted to evaluate the potential of circCRAMP1L, previously identified to be downregulated in preeclampsia, as a novel biomarker for predicting the development of preeclampsia.

Methods: We measured the expression of circCRAMP1L, which is reportedly relevant to trophoblast physiology, in plasma samples from 64 patients with preeclampsia and 64 age-, gestational age-, and body mass index-matched healthy pregnant women by qRT-PCR. MTT proliferation and transwell invasion assays revealed the biological role of circCRAMP1L in preeclampsia pathogenesis. RNA immunoprecipitation and dual-luciferase reporter assays clarified the mechanism underlying the biological function of circCRAMP1L in TEV-1 cells.

Results: circCRAMP1L circulating levels were significantly lower in patients with preeclampsia $(2.66 \pm 0.82, \Delta \mathrm{Ct}$ value) than in healthy pregnant women $(3.95 \pm 0.67, \Delta \mathrm{Ct}$ value, $p<0.001)$. The area under the receiver operating characteristic curve for circCRAMP1L was 0.813. Univariate and multivariate analyses identified circCRAMP1L as an independent predictor of preeclampsia. Furthermore, when circCRAMP1L was utilised in combination with its target protein macrophage stimulating protein (MSP), the predictive performance increased, with an area under the receiver operating characteristic curve of 0.928 (95\% Cl 0.882-0.974), 80.0\% sensitivity, and $80.0 \%$ specificity. The in vitro results indicated that circCRAMP1L regulates cell proliferation, and invasion via MSP and RON proteins. We investigated the molecular mechanisms of these effects. In vitro, relative to the control group, circCRAMP1L overexpression significantly enhanced cell proliferation; furthermore, trophoblast cell invasion increased proportionally with circCRAMP1L expression. RNA immunoprecipitation and luciferase reporter gene illustrated that circCRAMP1L participated in regulation of trophoblast cell by regulating MSP.

(Continued on next page)
\end{abstract}

\footnotetext{
* Correspondence: hlyang62@sina.com

2Department of Clinical Laboratory, Guangzhou Women and Children's

Medical Centre, Guangzhou Medical University, 9, Jinsui Road, Guangzhou

510623, China

Full list of author information is available at the end of the article
}

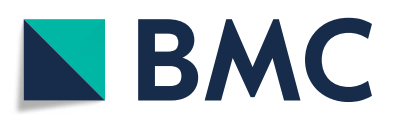

(c) The Author(s). 2020 Open Access This article is licensed under a Creative Commons Attribution 4.0 International License, which permits use, sharing, adaptation, distribution and reproduction in any medium or format, as long as you give appropriate credit to the original author(s) and the source, provide a link to the Creative Commons licence, and indicate if changes were made. The images or other third party material in this article are included in the article's Creative Commons licence, unless indicated otherwise in a credit line to the material. If material is not included in the article's Creative Commons licence and your intended use is not permitted by statutory regulation or exceeds the permitted use, you will need to obtain permission directly from the copyright holder. To view a copy of this licence, visit http://creativecommons.org/licenses/by/4.0/. The Creative Commons Public Domain Dedication waiver (http://creativecommons.org/publicdomain/zero/1.0/) applies to the data made available in this article, unless otherwise stated in a credit line to the data. 
(Continued from previous page)

Conclusion: Reduced plasma levels of circCRAMP1L may be associated with an increased risk of preeclampsia, and circCRAMP1L may be a novel biomarker of preeclampsia risk.

Keywords: circCRAMP1L, MSP/RON, Preeclampsia

\section{Background}

Preeclampsia (PE), a pregnancy-specific syndrome, has a worldwide incidence of approximately $2-8 \%$. With economic and social development, maternal and paternal ages are increasing, leading to larger number of cases of $\mathrm{PE}[1,2]$. PE can threaten the short-term or long-term health of mothers and their offspring [3, 4]. However, methods for preventing and treating PE remain ineffective [5]. Therefore, studies are urgently needed to clarify the pathogenesis of $\mathrm{PE}$, improve effective early interventions, reduce the risk of $\mathrm{PE}$, and lower the mortality of pregnant women and foetuses.

Recent studies showed that dysplasia of the placenta is a key factor in the pathogenesis of PE [6]. The theory holds that obstruction of the trophoblast differentiation phenotype during placenta formation leads to inadequate invasion and poor spiral artery remodelling, resulting in vascular endothelial cell damage, hypertension, and urinary protein in patients $[6,7]$. The main pathological manifestation of the placenta in patients with $\mathrm{PE}$ is that trophoblasts invade the endometrium too shallowly and only reach the decidual layer, providing experimental evidence for this theory [8].

In recent decades, the pathogenesis and prediction of PE have been widely evaluated by obstetric researchers [9]. The general international consensus is that early prevention and early intervention are the primary means of managing PE [10]; this requires effective prediction of the occurrence of PE. However, current prediction methods for PE remain limited and inefficient [5].

Circular RNA (circRNA) is a type of cyclic noncoding RNA. In contrast to traditional linear RNA, circRNA molecules have a closed ring structure that is not affected by RNA exonuclease [11]. These molecules are more stable, difficult to degrade, and exerts biological roles by directly regulating protein expression [12]. Numerous studies have reported that circRNA can affect cell proliferation, apoptosis, invasion, and metastasis [13, 14]. Previously, we and others found that circRNAs expressed in circulating blood and placenta tissue were related to $\operatorname{PE}[15,16]$. According to previous microarray analysis of circRNAs, circCRAMP1L was downregulated in PE blood. Through bioinformatics prediction and preexperiments, we found that circCRAMP1L can interact with macrophage stimulating protein (MSP). This study was conducted to investigate the role of
circCRAMP1L in PE and verify whether circCRAMP1L can be used as a biomarker for PE.

\section{Methods}

We carried out a prospective investigation of circCRAMP1L expression levels in PE and control. In the study, we followed up the pregnant women until one week postpartum. Then, we picked out who was diagnosed as PE and matched control with the maternal age, gestational age, and body mass index.

\section{Patient and samples}

The study was approved by the Medical Ethics Committees (permission number: 2018045) and written consent was acquired from enrolled subjects. All experimental steps follow the Helsinki declaration. PE and healthy control pregnancy or preterm labour (PTL) control samples were gathered from June 2017 to May 2019. A total of 1128 pregnant women were enrolled in the study. Inclusion criteria is that pregnancy women who were at 8-20 gestation weeks; exclusion conditions included trophoblastic disease, multiple pregnancies, individual taking medicine (particularly aspirin, antibiotics), alcohol intake, and diseases such as liver and kidney diseases.

Blood was collected and processed in accordance with the Standard Operating Procedures for Plasma Collection before 20th gestation weeks. Fresh peripheral venous blood samples $(5 \mathrm{~mL})$ were collected with EDTA and then centrifuged $(3000 \mathrm{rpm}$ for $10 \mathrm{~min}$ at $4{ }^{\circ} \mathrm{C}$ ). The plasma was immediately separated and stored at $-80^{\circ} \mathrm{C}$ until use. Thirty pairs of $\mathrm{PE}$ and PTL control placental samples were taken from combining quadrants of the maternal-foetal interface near the maternal side and stored in a liquid nitrogen tank after delivery.

\section{Fluorescent in situ hybridisation and immunohistochemistry}

Fluorescent in situ hybridisation analysis was performed as previously described [17]. Briefly, tissue was seeded on a coverslip, fixed with paraformaldehyde, and incubated with formamide, saline-sodium citrate buffer, Escherichia coli transfer RNA, salmon sperm DNA, bovine serum albumin, and DIG-labelled probe $\left(5^{\prime}\right.$-AATG CAACAAAGCTGAATGAACTCATTCAGGTTGGG AGCTGAAGGT - 3'). 
for circCRAMP1L junction. The probes for GAPDH were from a DIG Labelling Kit (MyLab Corporation, Beijing, China). Hybridisation was carried out in a humidified chamber. circCRAMP1L was detected with a Fluorescent In Situ Hybridisation Kit (RiboBio, Guangzhou, China), and the nuclei were counterstained with 4', 6-diamidino-2-phenylindole.

The expression of the target protein in the placenta specimen was detected with immunohistochemical method as previously described [18]. Briefly, Paraffin section of placenta were incubated with primary antibodies MSP or RON (Abcam, Cambridge, UK), then HRP staining kit carrying secondary antibody was used to stain. Sections were imaged by dedicated image microscope.

Western blotting, enzyme-linked immunosorbent assay, and real-time reverse transcription-quantitative PCR (realtime RT-qPCR)

Western blot was implemented as previously described [19]. Briefly, total proteins were extracted by RIPA Lysis Buffer (Beyotime, Shanghai, China) and quantified using a Pierce BCA Protein Assay Kit (Thermo Fisher Scientific, Waltham, MA, USA). These proteins were separated by $8-10 \%$ SDS-PAGE and transferred onto polyvinylidene difluoride membranes (Millipore, Billerica, MA, USA). The target proteins (MSP or RON) were immunoblotted with primary antibodies and then incubated with secondary antibodies coupled with HRP. The blots were photoed and quantitative analyzed using a immunoblotting imaging instrument.

MSP and RON levels in the plasma were estimated by enzyme-linked immunosorbent assay (catalogue no. ab76822 and ab70936); Abcam) according to the manufacturer's instructions. The lowest detectable MSP and RON concentrations were 8.0 and $8.0 \mathrm{pg} / \mathrm{mL}$, respectively.

Real-time RT-qPCR was performed with the PrimeScript $^{\text {Ti }}$ RT reagent kit (TaKaRa, Shiga, Japan) and Platinum SYBR Green qPCR SuperMix-UDG (Life
Technologies) following the manufacturer's instructions [20]. Divergent primers, rather than the more commonly used convergent primers, were designed for cirCCRAMP1L. The primers for circCRAMP1L and glyceraldehyde-3-phosphate dehydrogenase (GAPDH) were synthesised by Landm biotech (Guangzhou, China). The sequences of the GAPDH and circCRAMP1L primers were displayed into additional Table S1. the $\triangle \mathrm{Ct}$ method was used for the data analysis. All results are expressed as the mean \pm standard deviation of three independent experiments.

\section{TEV-1 cell culture}

TEV-1, a human extravillous trophoblast cell line, was gifted from The University of Hong Kong and The Chinese University of Hong Kong. TEV-1 was cultured in Dulbecco's modified Eagle's medium (DMEM)/F12 1:1 medium containing $5 \%$ foetal bovine serum according to manufacturer's instructions [21]. Briefly, stable TEV-1 cells were cultured up to $80 \%$ confluence and digested with trypsin. The suspended cells were grown in replaced culture liquid with F12: DMEM, HEPES, streptomycin, and 5\% foetal bovine serum (Life Technologies), followed by incubation in $5 \% \mathrm{CO}_{2}$ air at $37^{\circ} \mathrm{C}$.

\section{3-(4,5-dimethylthiazol-2-yl)-2,5-diphenyltetrazolium bromide (MTT) assay}

Trophoblast cell proliferation rates were evaluated by MTT assay [22]. The following groups were analysed in this experiment: si-MSP, si-RON, or circCRAMP1Loverexpressing group, and negative control group. TEV-1 cells were transfected with a circCRAMP1L-overexpressing vector or si-RON or si-MSP or empty vector and then seeded into a 96-well plate containing DMEM/F12 medium. On each day for up to five days, MTT solution (1 $\mathrm{mg} / \mathrm{mL}$ ) was added to the wells; after $6 \mathrm{~h}, 150 \mu \mathrm{L}$ dimethyl sulfoxide was added. Cell growth was measured at $490 \mathrm{~nm}$ on a SpectraMax i3x Microplate Reader (Molecular Devices, Sunnyvale, CA, USA).

Table 1 Clinical characteristics of patients with PE and normal pregnancies in plasma study

\begin{tabular}{|c|c|c|c|}
\hline Characteristic & $\mathrm{PE}(n=64)$ & Control $(n=64)$ & $P$-value \\
\hline Maternal Age (year) & $32.55 \pm 5.24$ & $31.26 \pm 4.86$ & 0.170 \\
\hline Pre-pregnancy BMI $\left(\mathrm{kg} / \mathrm{m}^{2}\right)$ & $23.07 \pm 2.14$ & $22.66 \pm 1.08$ & 0.085 \\
\hline Gestational age (week) & $34.45 \pm 3.37$ & $38.23 \pm 2.11$ & $<0.001$ \\
\hline Systolic (mmHg) & $156.27 \pm 14.39$ & $114.51 \pm 9.89$ & $<0.001$ \\
\hline Diastolic (mmHg) & $102.63 \pm 8.51$ & $76.73 \pm 8.09$ & $<0.001$ \\
\hline Proteinuria (> $0.3 \mathrm{~g} / 24 \mathrm{~h} \mathrm{n}, \%$ ) & 100 (100\%) & $0(0 \%)$ & $>0.05$ \\
\hline Smoking (n, \%) & $0(0 \%)$ & $0(0 \%)$ & $>0.05$ \\
\hline New-born weight (g) & $2459.16 \pm 678.24$ & $3466.5 \pm 534.28$ & $<0.001$ \\
\hline
\end{tabular}

PE preeclampsia, $B M I$ body mass index 
Table 2 Clinical characteristics of patients with PE and PTL control pregnancies in placenta study

\begin{tabular}{llll}
\hline Characteristic & PE $(\boldsymbol{n}=\mathbf{3 0})$ & Control $(\boldsymbol{n}=\mathbf{3 0})$ & $P$-value \\
\hline Maternal Age (year) & $32.23 \pm 4.16$ & $31.55 \pm 6.24$ & 0.210 \\
Pre-pregnancy BMI $\left(\mathrm{kg} / \mathrm{m}^{2}\right)$ & $22.92 \pm 3.07$ & $22.51 \pm 2.16$ & 0.079 \\
Gestational age $($ week) & $34.61 \pm 3.83$ & $34.23 \pm 2.11$ & 0.470 \\
Systolic $(\mathrm{mmHg})$ & $155.66 \pm 15.54$ & $118.72 \pm 8.72$ & $<0.05$ \\
Diastolic $(\mathrm{mmHg})$ & $103.01 \pm 7.73$ & $79.66 \pm 3.91$ & $<0.05$ \\
Proteinuria $(>0.3 \mathrm{~g} / 24 \mathrm{~h}, \mathrm{n}, \%)$ & $100(100 \%)$ & $0(0 \%)$ & $>0.05$ \\
Smoking $(\mathrm{n}, \%)$ & $0(0 \%)$ & $0(0 \%)$ & $>0.05$ \\
New-born weight (g) & $2433.75 \pm 538.19$ & $2512.7 \pm 681.46$ & 0.088 \\
\hline
\end{tabular}

PE preeclampsia, BMI body mass index, PTL unexplained preterm labour

\section{Invasion experiment}

Biocoat Matrigel Invasion Chambers (BD Biosciences, Franklin Lakes, NJ, USA) were applied to assess TEV-1 invasion [23]. TEV-1 cells $\left(1 \times 10^{6}\right.$ cells $\left./ \mathrm{mL}\right)$ were inoculated into the Matrigel-covered chambers and incubated in $500 \mu \mathrm{L}$ culture medium containing $20 \%$ serum for forty-eight hour. The invasion rooms were fixed and stained for $10 \mathrm{~min}$ and observed in microscopic method to evaluate the amount of invaded cells. To measure invasion changes under different conditions including circCRAMP1L + Si-RON, Si-MSP, or Si-RON.

\section{RNA immunoprecipitation (RIP)}

Binding of circCRAMP1L to MSP protein was detected utilizing the EZ-Magna RIP kit (Millipore) [24]. In accordance with the manufacturer's protocols, TEV-1 cells were seeded in fifteen centimetres' cell-plates, gathered with centrifugal method, and splitted into RIP lysed solution with $100 \mathrm{~mL}$ of buffer containing the lysates of $1-2 \times 10^{7}$ cells. Cell degradation products were put to use for immunoprecipitation in the company of antibodies against MSP (1:500) or RON (1:100) and normal immunoglobulin G (IgG; 1:100; ab109489, Abcam) and the target RNA was extracted and purified for analysis by RT-qPCR using primers specific for linc00473 and IgG (Supplementary TableS1).

\section{Double luciferase gene experiment}

Double luciferase gene experiment was executed to demonstrate the relevance of circCRAMP1L and MSP [22].
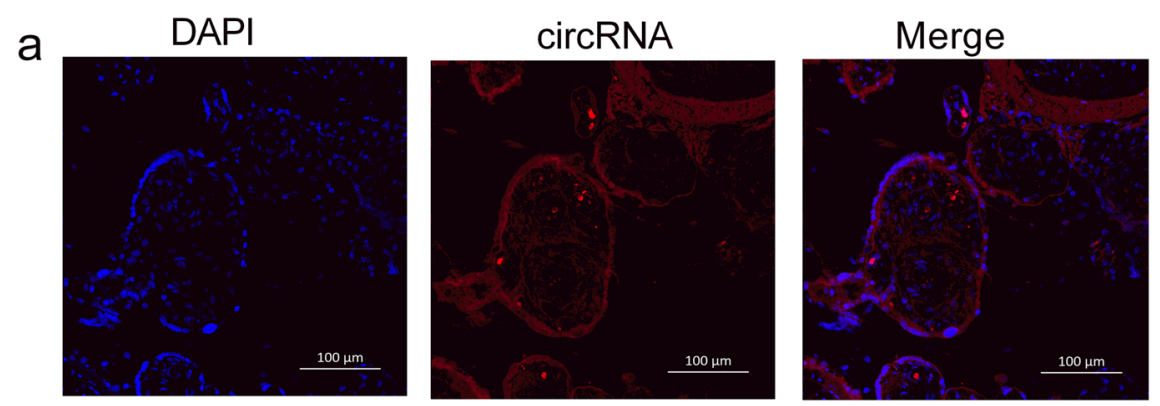

b
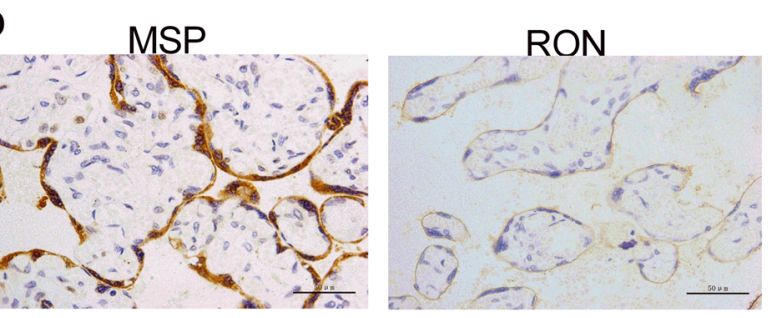

Neqative control

Villous tissue of placental

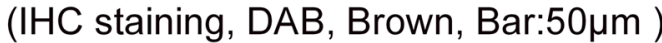

Fig. 1 a Fluorescent in situ hybridisation results showing the localisation of circCRAMP1L in placenta tissue and $\mathbf{b}$ immunohistochemistry analysis showing MSP and RON expression in villous tissue of placenta 

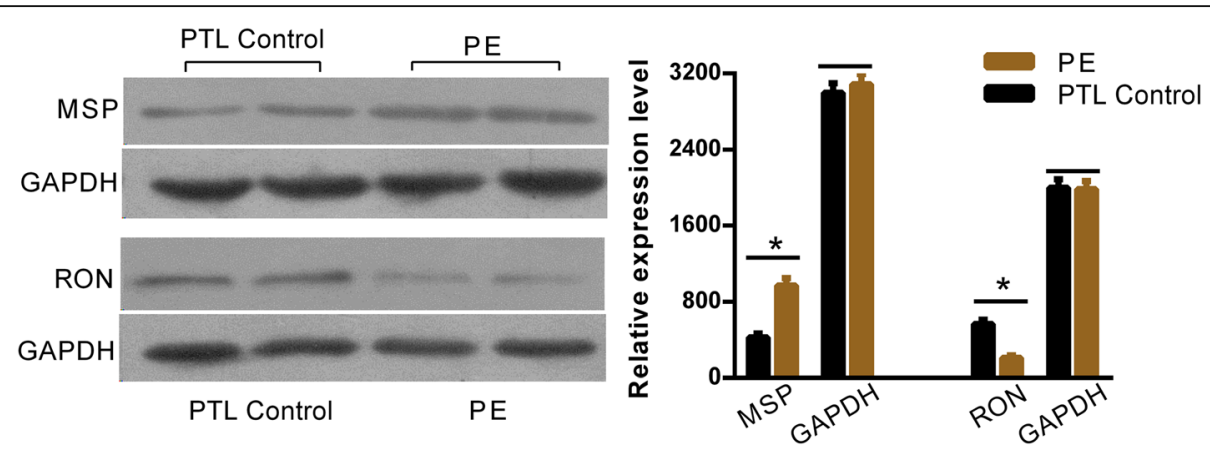

Fig. 2 Expression of MSP and RON protein levels determined by western blotting. MSP protein levels in PE placentas were substantially increased compared to in PTL pregnancy placentas, whereas RON protein levels showed the opposite expression patterns $\left({ }^{*} P<0.05\right)$

MSP-3' untranslated region (UTR) (including the seed sequence) cDNA fragments were amplified by PCR and then subcloned downstream of the luciferase genes in the pGL4 plasmid; this plasmid was named as pGL4MSP-3'UTR-WT. The mutant recombinant plasmids, named as pGL4-MSP-3'UTR-MUT (without objective sequence), were mutated by PCR mutation pattern. circCRAMP1L vectors or scrambled controls and MSP-3' UTR-WT or MSP-3'UTR-MUT were co-transfected into HEK293T cells. The wild-type MSP 3'UTR and mutant type MSP 3'UTR primer sequences are shown in Supplementary Table S2. At $48 \mathrm{~h}$ post-transfection, relative luciferase activity was normalised to Renilla luciferase activity and measured with a GloMax 96 Microplate Luminometer (Promega, Madison, WI, USA).

\section{Statistical analysis}

SPSS 24.0 software (SPSS, Inc., Chicago, IL, USA) and MedCalc 11.4. (MedCalc Software bvba, Ostend, Belgium) were used for statistical analyses. The

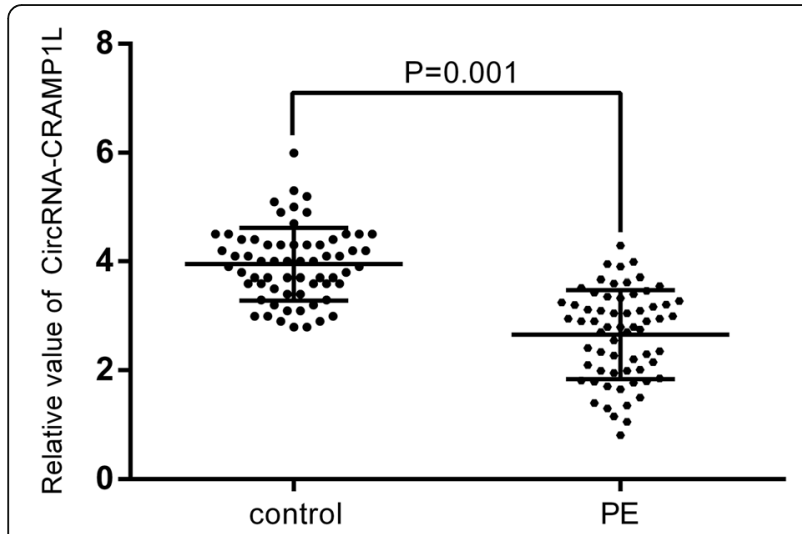

Fig. 3 circCRAMP1L expression in circulating plasma of patients with preeclampsia compared to normal pregnant women (2.66 $\pm 0.82 \mathrm{vs.}$ $3.95 \pm 0.67, P=0.001)$ independent sample $t$-test or Mann-Whitney U- test were performed for continuous data comparing and categorical data were analyzed by Fisher's exact test. All $P$ values are two-tailed and $P<0.05$ were regard as significant.

\section{Results}

The clinical characteristics of patients with PE, normal pregnancy controls, and PTL pregnancy controls are shown in Table 1 and Table 2. The fluorescent in situ hybridisation array verified the localisation of circCRAMP1L in the placenta tissue of patients with PE, which indicated that placenta circCRAMP1L is related to PE (Fig. 1a). Immunohistochemistry analysis revealed MSP and RON expression in the placental villous tissue (Fig. 1b). The differential expression of MSP and RON protein levels between PE placentas $(n=30)$ and PTL control placentas $(\mathrm{n}=30)$ was validated by western blot assays. As shown in Fig. 2, the MSP and RON protein

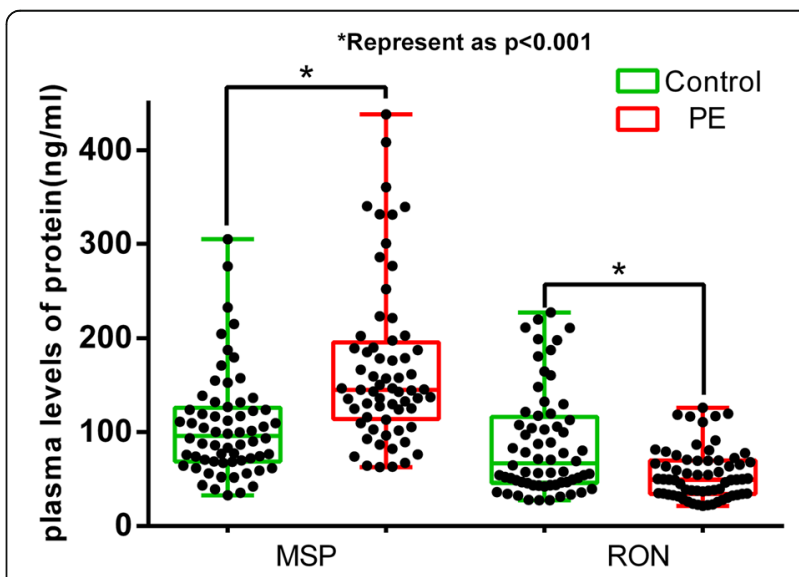

Fig. 4 Plasma MSP of PE group were significantly elevated than the control (170.25 \pm 42.11 vs. $106.44 \pm 38.31, \mathrm{ng} / \mathrm{mL}, P<0.001)$. In contrast, the plasma RON in PE group were significantly reduced than the control $(55.36 \pm 31.25$ vs. $87.41 \pm 27.48 \mathrm{ng} / \mathrm{mL}, \mathrm{P}<0.001)$ 


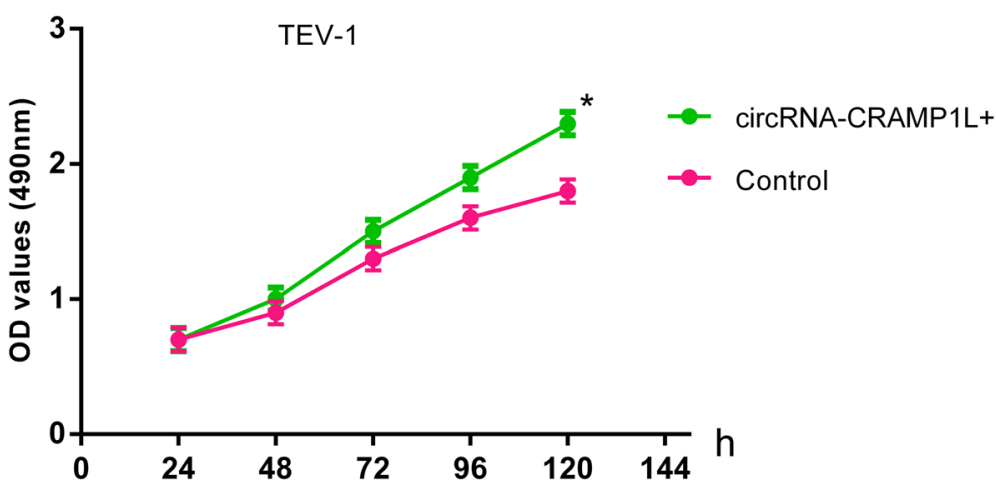

Fig. 5 Regulatory effects circCRAMP1L on trophoblast cell proliferation. Compared to the control group, cell proliferation was highly facilitated by circCRAMP1L overexpression ( ${ }^{*}$ compared with the control and $P<0.01$ )

levels in PE placentas were substantially increased and decreased, respectively, compared to in PTL pregnancy placentas (Fig. 2). Compared to the controls $(3.95 \pm 0.67$, $n=64)$, plasma circCRAMP1L level was significantly decreased in PE $(2.66 \pm 0.82, \mathrm{n}=64)(P<0.001)$, confirming that plasma circCRAMP1L derived from the placenta is closely related to PE pathogenesis (Fig. 3). Plasma MSP of PE group were significantly elevated than the control $(170.25 \pm 42.11$ vs. $106.44 \pm 38.31, \mathrm{ng} / \mathrm{mL}$, $\mathrm{P}<0.001$ ) (Fig. 4). In contrast, the plasma RON in PE group were significantly reduced than the control $(55.36 \pm 31.25$ vs. $\quad 87.41 \pm 27.48 \mathrm{ng} / \mathrm{mL}, \quad \mathrm{P}<0.001)$ (Fig. 4).

To provide insight into the biological function of cirCCRAMP1L in PE pathogenesis, MTT proliferation and transwell invasion assays were carried out. Compared to the control group, cell proliferation (Fig. 5) was greatly increased by circCRAMP1L overexpression; furthermore, the invasion of trophoblast cells, which were siRNARON TEV-1 cells, increased proportionally with the expression level of circCRAMP1L (Fig. 6); in contrast, cell proliferation in the siRNA-RON group and siRNA-MSP group was lessened than the siRNA-NC groups $(P<0.01)$. In the siRNA-RON group $(41.30 \pm 4.83$ cells $)$, cell invasion was inhibited compared to in the siRNANC group $(155.10 \pm 6.72$ cells, $\mathrm{P}<0.01)$ (Fig. 7), Similarly, cell invasion in the siRNA-MSP group (140.21 \pm 5.55) significantly differed from that in the siRNA-NC group $(27.62 \pm 3.48)(\mathrm{P}<0.01)$ (Fig. 8).

To further clarify the mechanism of circCRAMP1L, we performed RIP and dual-luciferase reporter assays using TEV-1 cells. The results indicated that circCRAMP1L mediates the regulation of cell proliferation and invasion via MSP and RON proteins, both which are closely related to the occurrence and development of PE (Figs. 9 and 10).

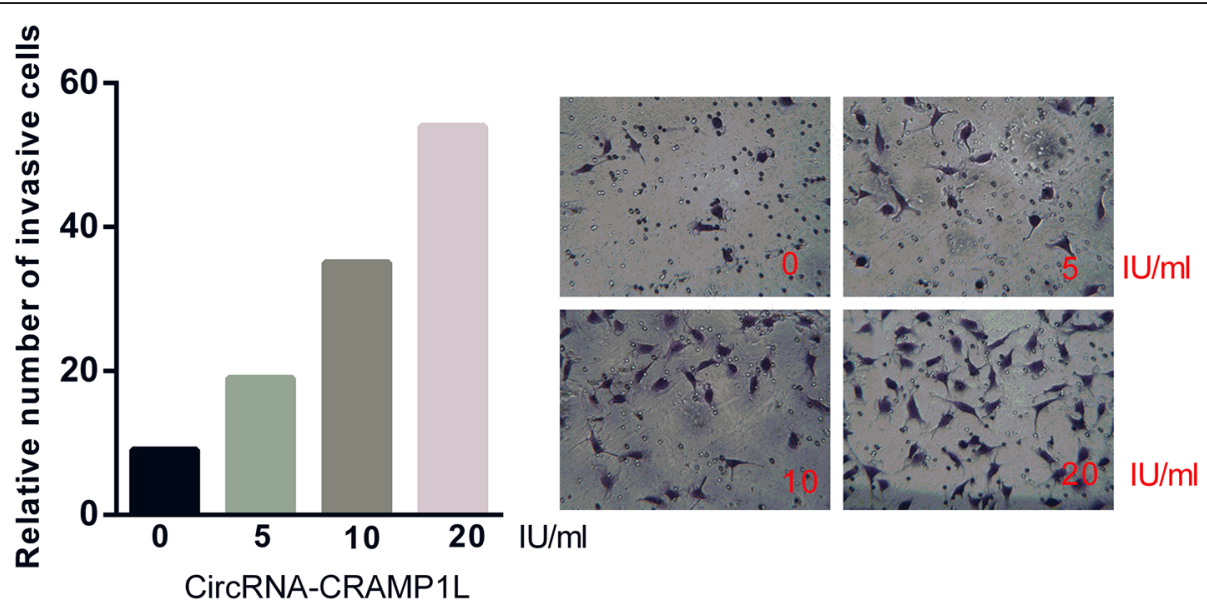

Fig. 6 Regulatory effects circCRAMP1L on trophoblast cell invasion. Invasion of trophoblast cells, which were TEV-1 cells treated with siRNA-RON, proportionally increased with the expression level of circCRAMP1L 


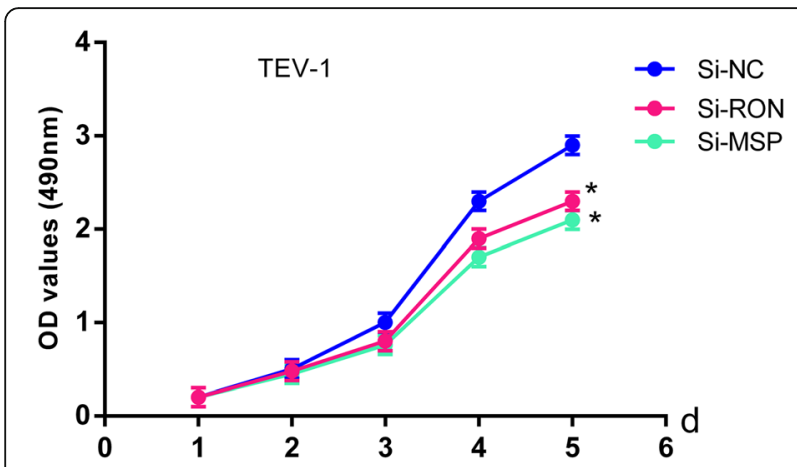

Fig. $\mathbf{7}$ Cell proliferation in siRNA-RON and siRNA-MSP groups was slower than in the siRNA-NC groups (* compared with the si-NC and $P<0.01)$

The area under the receiver operating characteristic curve (AUC) of circCRAMP1L was 0.813 (95\% confidence interval $[\mathrm{CI}]$ 0.731-0.895); its sensitivity and specificity were 64.0 and $74.0 \%$, respectively, and the cut-off value was 10.3 (cycle threshold value). However, taking the plasma MSP factor as a single predictor resulted in a sensitivity of $64 \%$, specificity of $62 \%$, and AUC of 0.721 (95\% CI 0.622-0.819) in PE. While MSP was utilised in conjunction with circCRAMP1L, the predictive performance of the AUC was up to 0.928 (95\% CI 0.882-0.974), with $80.0 \%$ sensitivity and $80.0 \%$ specificity (Fig. 11 ).

\section{Discussion}

PE is a complex disease for gravida and one of the leading causes of pregnancy-associated morbidity and mortality. The management of this syndrome requires improvement [25]. Reportedly, PE has a long-term impact on cardiovascular disease development [26]; hence, early detection and intervention are particularly important. Recently, increasing evidence has suggested that circRNA is associated with PE [27-29].

In the study, we found that circCRAMP1L was present in the placenta tissue of patients with PE. Bioinformatics prediction indicated that MSP is the target protein gene of circCRAMP1L. Furthermore, protein function analysis revealed that the MSP-RON axis may be involved in PE development. The role of MSP-RON in the growth and metastasis of tumours has already been reported extensively.

Some reports have shown that RON may be participated in the placental embedment [30,31]. We also observed that MSP and RON are differentially expressed in $\mathrm{PE}$ and control placenta and may be related to PE pathogenesis, which is consistent with our previous study [31].

Further, circCRAMP1L was obviously decreased in the circulating plasma of patients with PE compared to in controls. We performed used biological prediction and molecular experiments to verify that circCRAMP1L is involved in trophoblast cell proliferation and invasion via the MSP-RON axis in PE.

The MSP-RON axis is essential for placental development; previous animal experiments showed that foetal mice lacking RON were more likely to die from placental development problems [30]. MSP is the only ligand of RON, and MSP may be involved in placenta development. Analogously, we found that the placental cell proliferation and invasion capacity was lower when RON or MSP was knocked down (shRNA RON or MSP). It is well-known that placental development and placental trophoblast invasion are closely related to the pathogenesis of PE. MSP has been reported to promote the invasion of a variety of cells. However, we found that MSP was increased in the placental tissue of patients with PE, leading to decreased invasiveness. Literature review revealed that MSP can be divided into active and inactive

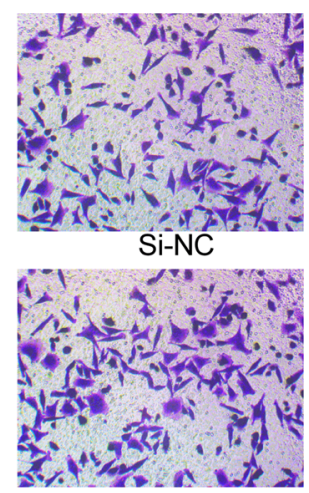

Si-NC

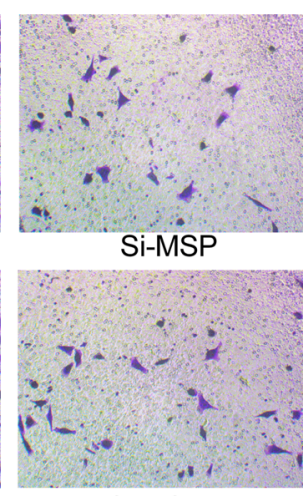

Si-RON

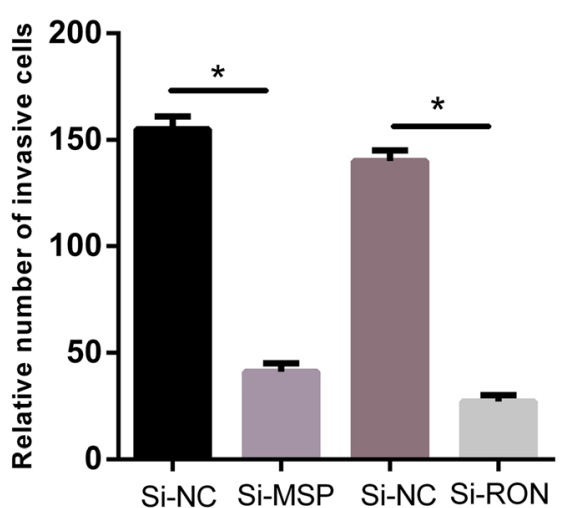

Fig. 8 TEV-1 Cell invasion capacities variation when siRNA-RON or siRNA-MSP. Cell invasion in the siRNA-RON group (41.30 \pm 4.83 cells) was inhibited compared to in the siRNA-NC group $\left(155.10 \pm 6.72\right.$ cells, $\left.{ }^{*} P<0.01\right)$. Similarly, cell invasion in the siRNA-MSP group (140.21 \pm 5.55$)$ significantly differed from that in the siRNA-NC group $(27.62 \pm 3.48)(* \mathrm{P}<0.01)$ 
a
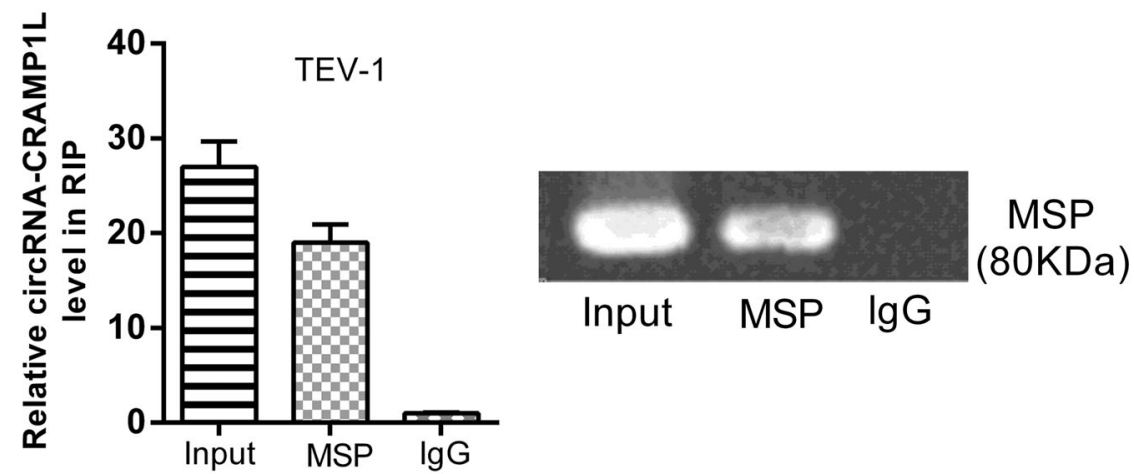

b
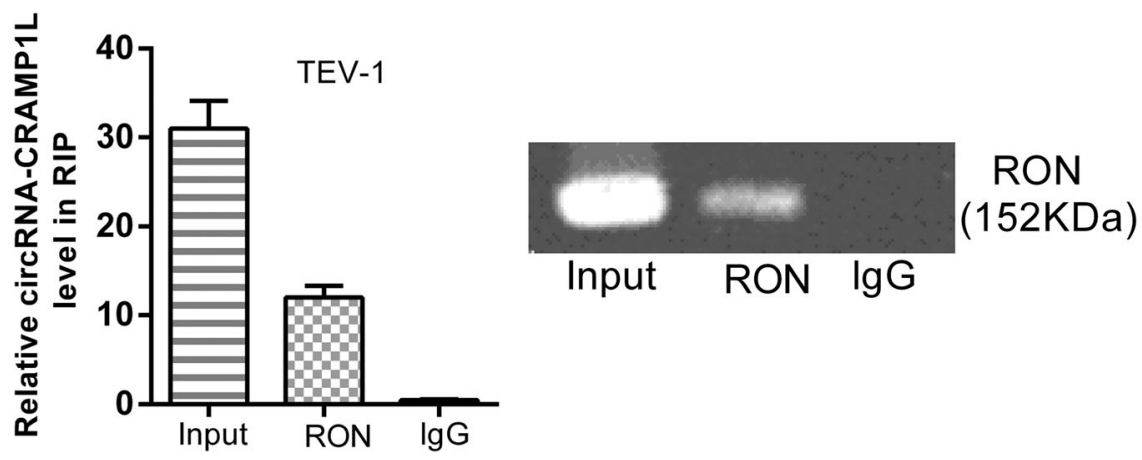

Fig. 9 RNA immunoprecipitation assay of the interaction of circCRAMP1L with MSP /RON in TEV-1 cells
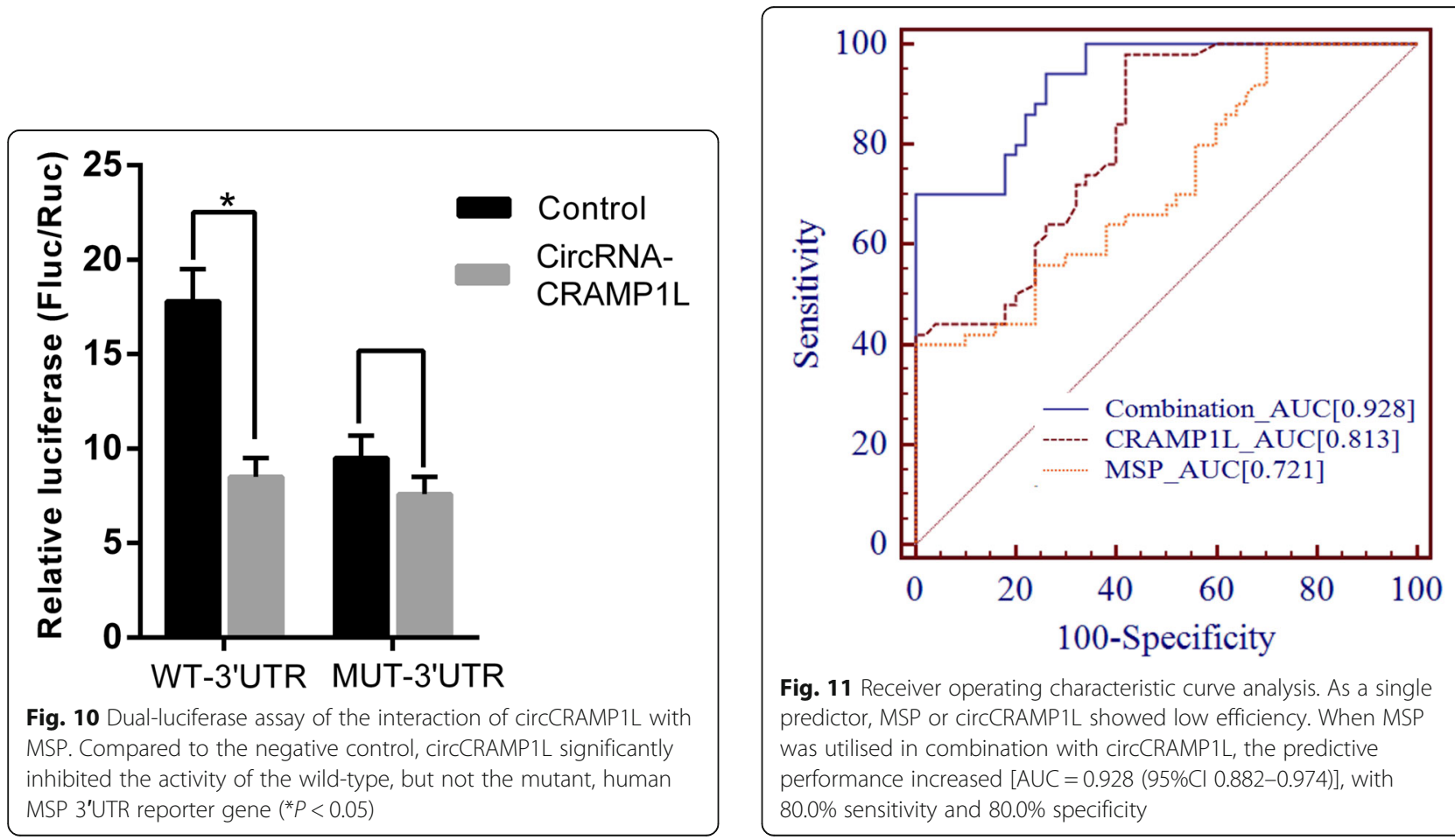

Fig. 11 Receiver operating characteristic curve analysis. As a single predictor, MSP or circCRAMP1L showed low efficiency. When MSP was utilised in combination with circCRAMP1L, the predictive performance increased [AUC $=0.928(95 \% \mathrm{Cl} 0.882-0.974)]$, with $80.0 \%$ sensitivity and $80.0 \%$ specificity 
types [32]. The decrease in circCRAMP1L may have inhibited activation of MSP and led to a decrease in RON. However, the increasing MSP detected in the placenta and plasma may have inactive. This would explain why MSP was increased whereas RON was decrease. Further experiments are needed to be clarify this point.

Through this preliminary study, we confirmed that reduced circCRAMP1L influenced the physiological function of trophoblast cells via MSP/RON axis and that circCRAMP1L/MSP/RON may play a role in PE pathogenesis. Additionally, circCRAMP1L, together with the downstream protein factor MSP, may heighten the ability to predict PE.

There are two limitations in the study. Smaller sample size was first restriction, and thus we did not classify the different types of PE. Second, we only analysed the total increase in MSP. Further studies are needed to distinguish active from inactive MSP and determine how circCRAMP1L affects MSP activation.

\section{Conclusions}

In conclusion, circCRAMP1L may be beneficial for preventing and treating PE and may be a novel biomarker for PE. Further studies of the specific and downstream mechanisms are needed, and the efficacy of using more predictive factors jointly should be examined.

\section{Supplementary information}

Supplementary information accompanies this paper at https://doi.org/10. 1186/s12884-020-03345-5.

Additional file 1: Supplementary Table S1. Primer sets used for RT$P C R, q R T-P C R$, and RNA immunoprecipitation (RIP). Supplementary Table S2. Primer sets used for Dual-luciferase reporter assay.

Additional file 2: Fig. S1. Original images of western blot (the cropping blot images correspond to fig 2 in manuscript, the samples derive from the same experiment and that blots were processed in parallel.). Fig. S2. Original images of RNA immunoprecipitation(RIP) experiment (the agarose gel images correspond to fig9 in manuscript).

\footnotetext{
Abbreviations

circRNAs: circular RNAs; circCRAMP1L: circRNA-CRAMP1L; MTT: 3-(4,5dimethylthiazol-2-yl)-2,5-diphenyltetrazolium bromide; RIP: RNA immunoprecipitation; TEV-1: Human first-trimester extravillous trophoblast cell line; AUC: Area under the receiver operating characteristic curve; MSP: Macrophage stimulating protein; RON: Recepteur d'origine nantais, receptor of macrophage stimulating protein; PE: Preeclampsia; PTL: Unexplained preterm labour; BMI: Body mass index;

EDTA: Ethylenediaminetetraacetic acid; FISH: Fluorescent in situ hybridisation; DAPI: 4', 6-diamidino-2-phenylindole; GAPDH: Glyceraldehyde-3-phosphate dehydrogenase; DIG: Digoxigenin; RT-qPCR: Reverse transcription-quantitative polymerase chain reaction; SDS-PAGE: Sodium dodecyl sulfatepolyacrylamide gel electrophoresis; HRP: Horseradish peroxidase; SYBR: A fluorescent dye; DMEM: Dulbecco's modified Eagle's medium; HEPES: 2-[4-(2hydroxyethyl)piperazin-1-yl]ethanesulfonic acid; DMSO: Dimethylsulfoxide; IgG: Immunoglobulin G; MUT: Mutant; UTR: Untranslated region; GO: Gene Ontology; IOD [Ave]: Accumulated optical density (average); ROC: Receiver operating characteristic; CT: Cycle threshold
}

\section{Acknowledgements}

We appreciate Dr. Long for providing vectors and biological sample bank of GZWCMC for supplying placenta.

\section{Authors' contributions}

Conception and design: YZ1, HY. Development of methodology: YZ1, HY. Acquisition of data: JS, RC. Analysis and interpretation of data: YZ1, HY, YZ2. Writing, review, and/or revision of the manuscript: YZ1, HY. Administrative, technical, or material support: YZ2. Study supervision: HY. All Authors read and approved the manuscript

\section{Funding}

This work was supported by the National Natural Science Foundation of China (81801474), the National Natural Science Fund of China (81871716), the Science and Technology Fund of Shenzhen (JCYJ20180306172502097), Science and technology special fund of Longhua District (2017096) and The Science and Technology Fund of Guangzhou (201707010019). These funders just provide funds and not undertake other roles.

\section{Availability of data and materials}

The detailed datasets used and analysed during the current study are available from the corresponding author on reasonable request.

\section{Ethics approval and consent to participate}

This study was approved by the Medical Ethics Committees of the Shenzhen Longhua District Central (approval number: 2018045). All procedures were undertaken in accordance with guidelines set forth by the Declaration of Helsinki. Informed written consent was obtained from all participants.

\section{Consent for publication}

Not applicable.

\section{Competing interests}

No potential conflicts of interest were disclosed.

\section{Author details}

'Department of Clinical Laboratory, Shenzhen Longhua District Central Hospital, Guangdong Medical University, Shenzhen 518110, Guangdong, China. ${ }^{2}$ Department of Clinical Laboratory, Guangzhou Women and Children's Medical Centre, Guangzhou Medical University, 9, Jinsui Road, Guangzhou 510623, China.

Received: 22 April 2020 Accepted: 16 October 2020

Published online: 27 October 2020

\section{References}

1. Casteleiro A, Paz-Zulueta M, Parás-Bravo P, Ruiz-Azcona L, Santibañez M. Association between advanced maternal age and maternal and neonatal morbidity: a cross-sectional study on a Spanish population. PLoS One. 2019; 14:e0225074.

2. Khandwala YS, Baker VL, Shaw GM, Stevenson DK, Lu Y, Eisenberg ML Association of paternal age with perinatal outcomes between 2007 and 2016 in the United States: population based cohort study. BMJ. 2018; $363: k 4372$.

3. Chappell LC, Brocklehurst P, Green ME, Hunter R, Hardy P, Juszczak E, et al. Planned early delivery or expectant management for late preterm pre-eclampsia (PHOENIX): a randomised controlled trial. Lancet. 2019; 394:1181-90.

4. Lane-Cordova AD, Khan SS, Grobman WA, Greenland P, Shah SJ. Long-term cardiovascular risks associated with adverse pregnancy outcomes: JACC review topic of the week. J Am Coll Cardiol. 2019;73:2106-16.

5. Practice Bulletin No ACOG. 202: gestational hypertension and preeclampsia. Obstet Gynecol. 2019;133:e1-e25.

6. Burton GJ, Redman CW, Roberts JM, Moffett A. Pre-eclampsia: pathophysiology and clinical implications. BMJ. 2019;366:12381.

7. Seki H. Balance of antiangiogenic and angiogenic factors in the context of the etiology of preeclampsia. Acta Obstet Gynecol Scand. 2014:93:959-64.

8. Raguema N, Moustadraf S, Bertagnolli M. Immune and apoptosis mechanisms regulating placental development and vascularization in preeclampsia. Front Physiol. 2020;11:98. 
9. Okwudire EG, Atalabi OM, Ezenwugo UM. The use of uterine artery doppler indices for prediction of pre-eclampsia in port-Harcourt. Nigeria Niger Postgrad Med J. 2019;26:223-9.

10. Webster K, Fishburn S, Maresh M, Findlay SC. Chappell LC; Guideline Committee Diagnosis and management of hypertension in pregnancy: summary of updated NICE guidance. BMJ. 2019;366:15119.

11. Kristensen LS, Andersen MS, Stagsted LW, Ebbesen KK, Hansen TB, Kjems J. The biogenesis, biology and characterization of circular RNAs. Nat Rev Genet. 2019;20:675-91..

12. Fasolo F, Di Gregoli K, Maegdefessel L, Johnson JL. Non-coding RNAs in cardiovascular cell biology and atherosclerosis. Cardiovasc Res. 2019;115: 1732-56.

13. Hanniford D, Ulloa-Morales A, Karz A, Berzoti-Coelho MG, Moubarak RS, Sánchez-Sendra B, et al. Epigenetic Silencing of CDR1as Drives IGF2BP3-Mediated Melanoma Invasion and Metastasis. Cancer Cell. 2020;37:55-70 e15.

14. Xiao MS, Ai Y, Wilusz JE. Biogenesis and functions of circular RNAs come into focus. Trends Cell Biol. 2020;30:226-40.

15. Zhang YG, Yang HL, Long Y, Li WL. Circular RNA in blood corpuscles combined with plasma protein factor for early prediction of pre-eclampsia. BJOG. 2016;123:2113-8.

16. Zhou W, Wang H, Wu X, Long W, Zheng F, Kong J, et al. The profile analysis of circular RNAs in human placenta of preeclampsia. Exp Biol Med. 2018; 243:1109-17.

17. Chatterjee S, Li W, Wong CA, Fisher-Adams G, Lu D, Guha M, et al. Transduction of primitive human marrow and cord blood-derived hematopoietic progenitor cells with adeno-associated virus vectors. Blood. 1999;93:1882-94.

18. Abbas Y, Carnicer-Lombarte A, Gardner L, Thomas J, Brosens JJ, Moffett A, Sharkey AM, Franze K, Burton GJ, Oyen ML. Tissue stiffness at the human maternal-fetal interface. Hum. Reprod. 2019;34:1999-2008.

19. Depoix CL, Colson A, Hubinont C, Debieve F. Impaired vascular endothelial growth factor expression and secretion during in vitro differentiation of human primary term cytotrophoblasts. Angiogenesis. 2020;23:221-30.

20. Yang F, Fang E, Mei H, Chen Y, Li H, Li D, Song H, Wang J, Hong M, Xiao W, Wang $X$, Huang $K$, Zheng $L$, Tong Q. Cis-acting promotes $\beta$-catenin signaling and Cancer progression via DDX3-mediated transactivation of YY1. Cancer Res. 2019;79:557-71.

21. Zhang Y, Yang H, Zhang YP, Shi J, Chen R, Xiao X. CircSFXN1 regulates the behaviour of trophoblasts and likely mediates preeclampsia. Placenta. 2020; 101:115-23.

22. Zhang Y, Huang G, Zhang YP, Yang H, Long Y, Liang Q, Zheng Z. MiR-942 decreased before 20 weeks gestation in women with preeclampsia and was associated with the pathophysiology of preeclampsia in vitro. Clin Exp Hypertens. 2017;39:108-13.

23. Zheng J, Qu D, Wang C, Ding L, Zhou W. Involvement of CXCL12/CXCR4 in the motility of human first-trimester endometrial epithelial cells through an autocrine mechanism by activating PI3KJAKT signaling. BMC Pregnancy Childbirth. 2020;20:87

24. Hu X, Ao J, Li X, Zhang H, Wu J, Cheng W. Competing endogenous RNA expression profiling in pre-eclampsia identifies hsa_circ_0036877 as a potential novel blood biomarker for early pre-eclampsia. Clin Epigenetics. 2018;10:48.

25. Hinkosa L, Tamene A, Gebeyehu N. Risk factors associated with hypertensive disorders in pregnancy in Nekemte referral hospital, from July 2015 to June 2017, Ethiopia: case-control study. BMC Pregnancy Childbirth. 2020;20:16.

26. Fox R, Kitt J, Leeson P, Aye CYL, Lewandowski AJ. Preeclampsia: risk factors, diagnosis, management, and the cardiovascular impact on the offspring. J Clin Med. 2019;8:1625.

27. Zhou B, Zhang X, Li T, Xie R, Zhou J, Luo Y, et al. CircZDHHC20 represses the proliferation, migration and invasion in trophoblast cells by miR-144/ GRHL2 axis. Cancer Cell Int. 2020;20:19.

28. Shen XY, Zheng LL, Huang J, Kong HF, Chang YJ, Wang F, et al. CircTRNC18 inhibits trophoblast cell migration and epithelial-mesenchymal transition by regulating miR-762/Grhl2 pathway in pre-eclampsia. RNA Biol. 2019;16: $1565-73$.

29. Li W, Yu N, Fan L, Chen SH, Wu JL. Circ_0063517 acts as ceRNA, targeting the miR-31-5p-ETBR axis to regulate angiogenesis of vascular endothelial cells in preeclampsia. Life Sci. 2020;244:117306.
30. Hess KA, Waltz SE, Chan EL, Degen SJ. Receptor tyrosine kinase Ron is expressed in mouse reproductive tissues during embryo implantation and is important in trophoblast cell function. Biol Reprod. 2003;68:1267-75.

31. Zhang $Y$, Yang $H$, Long $Y$, Ma Q, Chen R. Plasma level of placenta-derived macrophage-stimulating protein -chain in preeclampsia before 20 weeks of pregnancy. PLoS One. 2016;11:e0161626.

32. Millar R, Kilbey A, Remak SJ, Severson TM, Dhayade S, Sandilands E, Foster K, Bryant DM, Blyth K, Coffelt SB. The MSP-RON axis stimulates cancer cell growth in models of triple negative breast cancer. Mol Oncol. 2020;14: 1868-80.

\section{Publisher's Note}

Springer Nature remains neutral with regard to jurisdictional claims in published maps and institutional affiliations.
Ready to submit your research? Choose BMC and benefit from:

- fast, convenient online submission

- thorough peer review by experienced researchers in your field

- rapid publication on acceptance

- support for research data, including large and complex data types

- gold Open Access which fosters wider collaboration and increased citations

- maximum visibility for your research: over $100 \mathrm{M}$ website views per year

At $\mathrm{BMC}$, research is always in progress.

Learn more biomedcentral.com/submissions 